\title{
Polyurethane pressure-sensitive adhesives as raw materials for the manufacturing of protective films
}

\author{
Monika Lągiewczyk, Zbigniew Czech* \\ * West Pomeranian University of Technology Szczecin, Institute of Organic Chemical Technology, ul. Pułaskiego 10, \\ Pl 70-322 Szczecin, Poland, e-mail address: psa_czech@wp.pl
}

\begin{abstract}
The present paper relates to water-borne polyurethane pressure-sensitive adhesives (PU-PSA) systems for self-adhesive protective films, and methods of their preparation. The typical protective films are self-adhesive films with excellent removability. Their manufacture is a film conversion process using common materials developed for the packaging industry (PVC and polyolefins). The most often used carrier for the constructions of protective films is PE. Polyurethane PSA layers are characterized by constant low peel adhesion between 3 and $5 \mathrm{~N} / 2,5 \mathrm{~cm}$.
\end{abstract}

Keywords: polyurethane, self-adhesive, protective films, peel adhesion.

\section{INTRODUCTION}

Protective films are packaging materials in a functional, rather than a legislative sense. They differ from classical packaging materials, where functionality concerns the protection of the product during transport and storage, and other aesthetic, publicity-related design characteristics. Protective films are laminable, self-adhesive materials. They are different from the products for the pressuresensitive adhesives (PSA) converting industry, where selfadhesively or pressure-sensitivity is used to characterize the bond-forming of a special adhesive class. In the classical variant the self-adhesive performances of the film will be achieved via PSA coating ${ }^{-3}$.

For the commercially used PSA with excellent performances synthetic polymers based on acrylics, rubber, silicones, polyurethanes, polyesters and polyether ${ }^{4}$ are preferred (Fig. 1).

Polyurethane pressure-sensitive adhesive fulfil many of the industry's most severe requirements in terms of performance, environment and easy of practical application. They have been widely used in self-adhesives, sealants and electrical products owing to their low glass transition temperature $\left(\mathrm{T}_{\mathrm{g}}\right)$ between -40 and $-60^{\circ} \mathrm{C}$, hydrophobicity, acid-based resistance and excellent dielectric properties5.

Protective films are generally monowebs, having carrier film as a main component. The self-adhesive performances of the film will be achieved via the PSA coating. Their manufacture is a film conversion process using common materials developed for the packaging industry

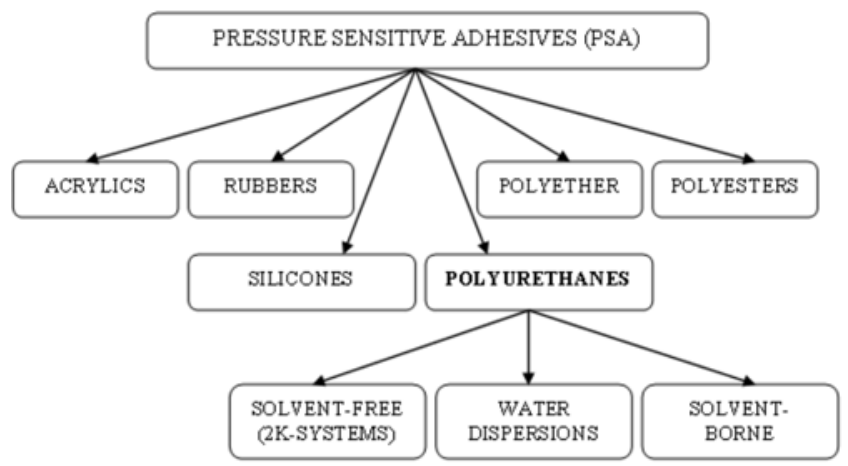

(PVC and polyolefins). The most used carrier for the construction of protective films is PE. The acrylic PSA, specially developed for the PE carrier are characterised by law adhesion between 3 and $5 \mathrm{~N} / 2.5 \mathrm{~cm}^{6}$.

\section{EXPERIMENTAL}

The synthesis of the novel water-dispersible polyurethane PSA based on hydroxylated polybutadiene (HTPB), polypropylene glycol (PPG), dimethylolpropionic acid (DMPA) and isophorone diisocyanate (IPDI) catalyzed by dibutyltin dilaurate (DBTL) was carried out in the absence of a solvent at about $85^{\circ} \mathrm{C}$ for $2 \mathrm{~h}$ under nitrogen atmosphere.

After the period, the temperature was reduced to $85^{\circ} \mathrm{C}$ and aliquots were removed from the bulk for the NCO content determination. The synthesized polyurethane polymer neutralization with triethylamine (TEA) was proceeded at $50^{\circ} \mathrm{C}$ for $1 \mathrm{~h}$, the temperature was reduced to $25^{\circ} \mathrm{C}$ and the polyurethane dispersion of the bulk in water was performed at high-speed stirring. Afterwards, ethylenediamine (EDA) was added to the dispersion that was kept at about $35^{\circ} \mathrm{C}$ for $1 \mathrm{~h}$ to complete the chain-extension reaction between the amino groups of the chain extender and the $\mathrm{NCO}$ end groups of the polyurethane polymer. Figure 2 shows the aqueous polyurethane dispersion synthesis scheme.

Aqueous polyurethane PSA dispersions with a solid content of about 40 to $60 \mathrm{wt}$.\% were obtained by varying the hydroxylated polybutadiene (HTPB) content from 20 to $50 \mathrm{wt} . \%$, dimethylolpropionic acid (DMPA) from 2 to $6 \mathrm{wt} . \%$.

The isocyanates are very important for the introduction of urethane groups into the polymer. Depending on their structure, the final properties of the polymer are influenced. Beside isophorone diisocyanate (IPDI), cycloaliphatic dicyclohexylmethane (HMDI) and aliphatic diisocyanate 2,2,4-trimethyl-hexamethylene diisocyanate (TMDI) are used (Table 1). The aromatic toluene diisocyanate (TDI) and diphenylene diisocyanate (PPDI) are more difficult to handle. It is the result of their high reactivity of water. Some of the newer production processes allow them to be built in. 

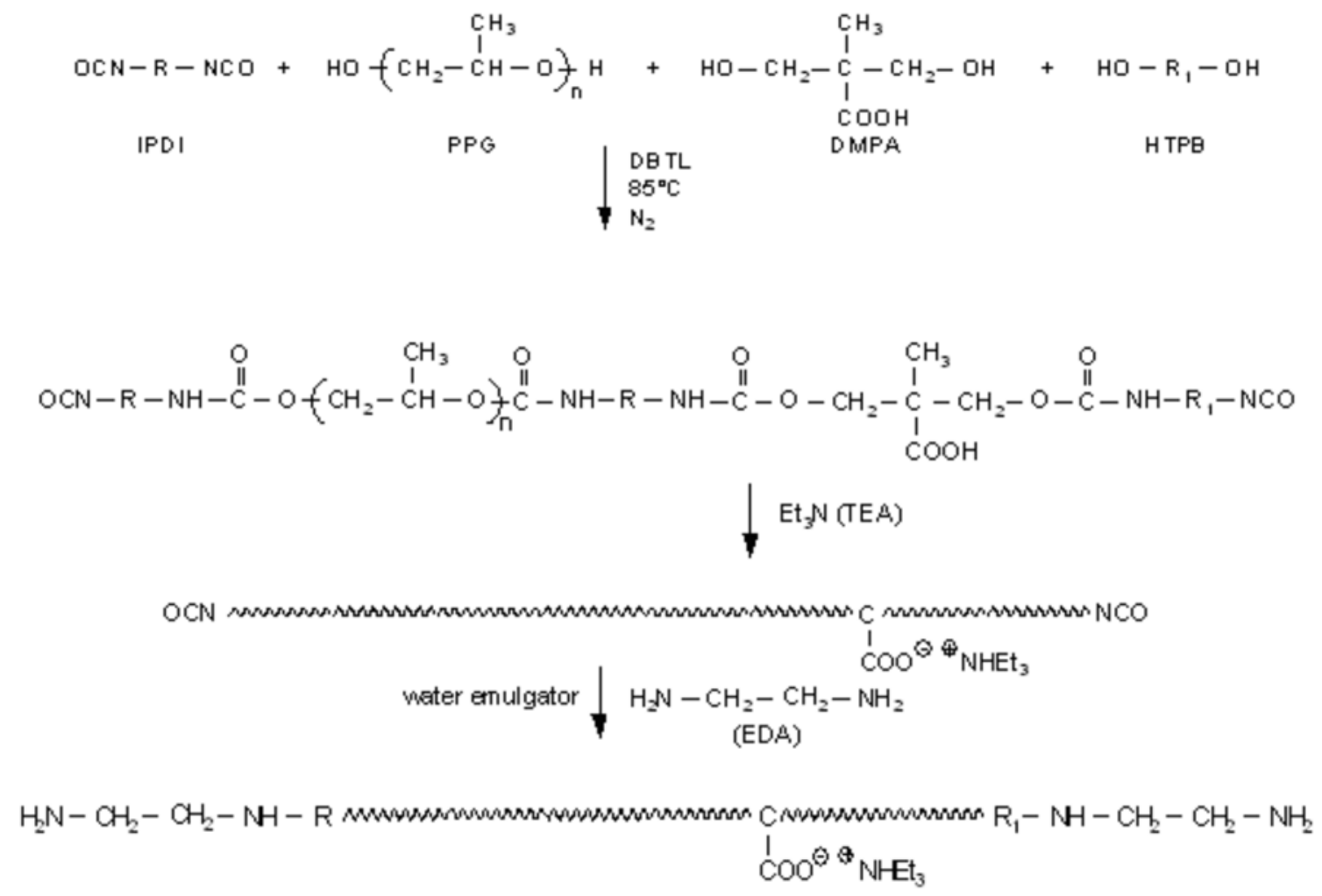

Figure 2. Polyurethane aqueous PSA dispersion synthesis

Table 1. Diisocyanates used by synthesis of aqueous polyurethane adhesives

\begin{tabular}{|c|c|c|c|}
\hline Diisocyanate & $\begin{array}{c}\text { Polymer content } \\
{[\mathrm{wt} . \%]}\end{array}$ & $\begin{array}{l}\text { Viscosity } \\
\text { [mPas] }\end{array}$ & Remarks \\
\hline IPDI & 40 & 80 & $\begin{array}{c}\text { stable }>12 \\
\text { months }\end{array}$ \\
\hline IPDI & 45 & 210 & $\begin{array}{c}\text { stable }>12 \\
\text { months }\end{array}$ \\
\hline HMDI & 40 & 110 & $\begin{array}{c}\text { stable }>12 \\
\text { months }\end{array}$ \\
\hline TMDI & 40 & 90 & $\begin{array}{c}\text { stable }>12 \\
\text { months }\end{array}$ \\
\hline TMDI & 45 & 300 & $\begin{array}{c}\text { stable }>12 \\
\text { months }\end{array}$ \\
\hline TMDI & 50 & 850 & $\begin{array}{c}\text { stable }>12 \\
\text { months }\end{array}$ \\
\hline TMDI & 55 & 3200 & $\begin{array}{c}\text { stable }>12 \\
\text { months }\end{array}$ \\
\hline TMDI & 60 & 8400 & $\begin{array}{c}\text { stable }>12 \\
\text { months }\end{array}$ \\
\hline
\end{tabular}

All the synthesised aqueous PU-PSA are characterised through an acceptable pot-life of at least 12 months. The high solid aqueous PU-PSAs are specified as the high viscosity PU-PSA water dispersions (Fig. 3). Their practical acceptable viscosity allows their direct coating on the dehesive carrier without the addition of the usually wetting and thickening agents.

The aqueous PU-PSA dispersion, the formulation containing 2.0 wt.\% DMPA, 20.0 wt.\% Voranol 1010, 5.0 wt. $\%$ HTPB, 7.0 wt. $\%$ IPDI, 0.4 wt. $\%$ DBTL, 1.0 wt. $\%$ TEA, 60 wt.\% distilled water, 0.2 wt.\% EDA and 4.4 wt.\% emulsifier Dowfax, was selected as raw material for protective films.

Pressure-sensitive adhesives are considered removable if they are removed cleanly from a test substrate without causing any damage to the test substrate over a range of

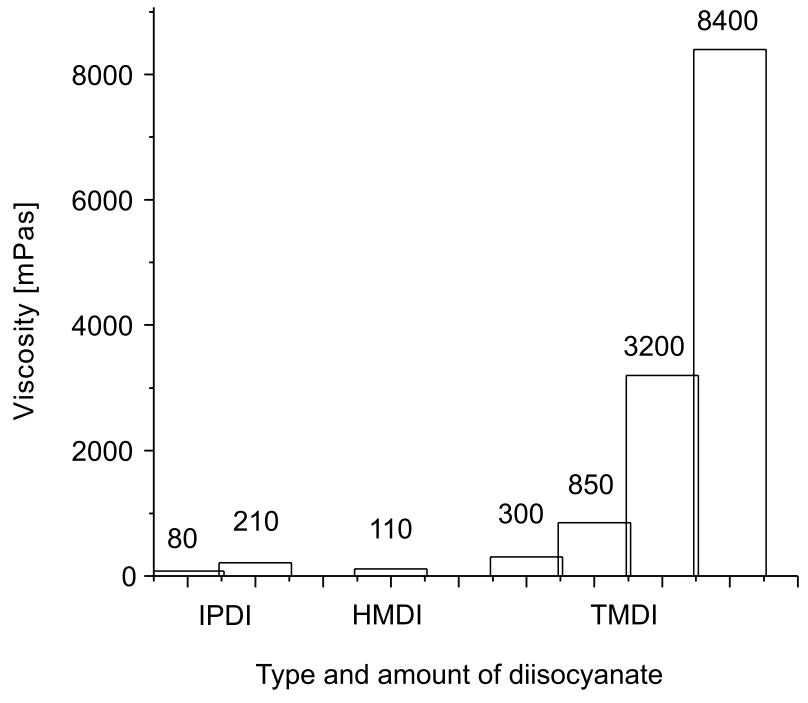

Figure 3. The viscosity of synthesised aqueous PU-PSA

peel rates and varied periods of dwell at room temperature.

One should also note the unusual adhesive properties which are very difficult to define by the AFERA methods (Association des Fabricants Europeens de Rubans AutoAdhesifs) procedures. The exact details can be found in AFERA 4001 (peel adhesion-the measure for removability), AFERA 4012 (shear strength) and AFERA 4015 (tack).

\section{RESULTS AND DISCUSSION}

The developed polyurethane pressure-sensitive adhesives were crosslinked with the following commercial multifunctional isocyanates: Basonate FDS 3425 (1,1 methylenebis(4-isocyanato-cyclohexane) from BASF), Basonate F 200 WD (aliphatic polyisocyanate from BASF) 
and Desmodur N 3200 (aliphatic polyisocyanate resin based on hexamethylene diisocyanate from Bayer) at the levels of 1,3,5 and to $7 \mathrm{wt} . \%$ according to polyurethane polymer. Because the crosslinking reaction proceeds at room temperature, the isocyanate must be added and mixed just before the coating operation with $30 \mathrm{~g} / \mathrm{m}^{2}$ coat weight dry polymer on polyester film. A pressure-sensitive adhesive layer of the PU-PSA water dispersion on the polyester film was dried in an oven at $105^{\circ} \mathrm{C}$ for 10 minutes.

A typical example of the effect of the used multifunctional isocyanate crosslinking agents on the tack and the peel adhesion, measured as removability level, is shown in Figs. 4 and 5.

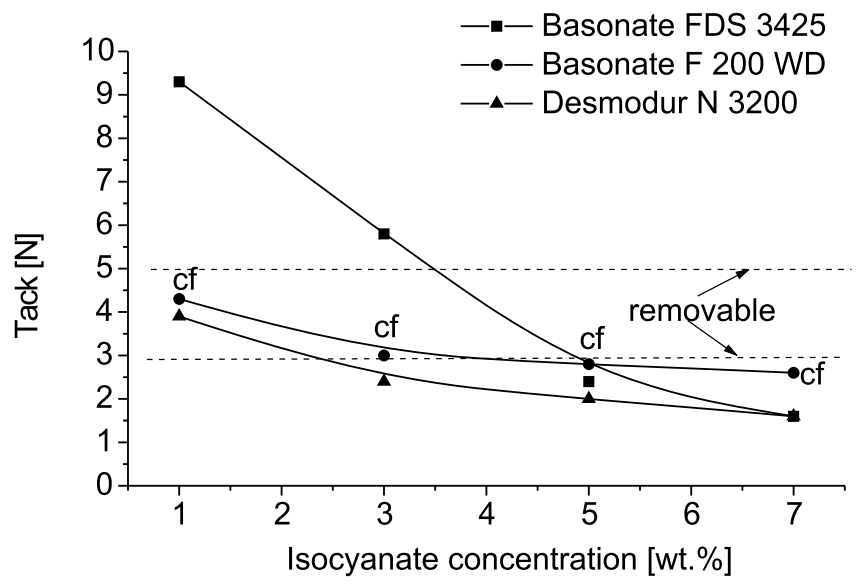

Figure 4. The effect of concentration and type of multifunctional isocyanates on tack

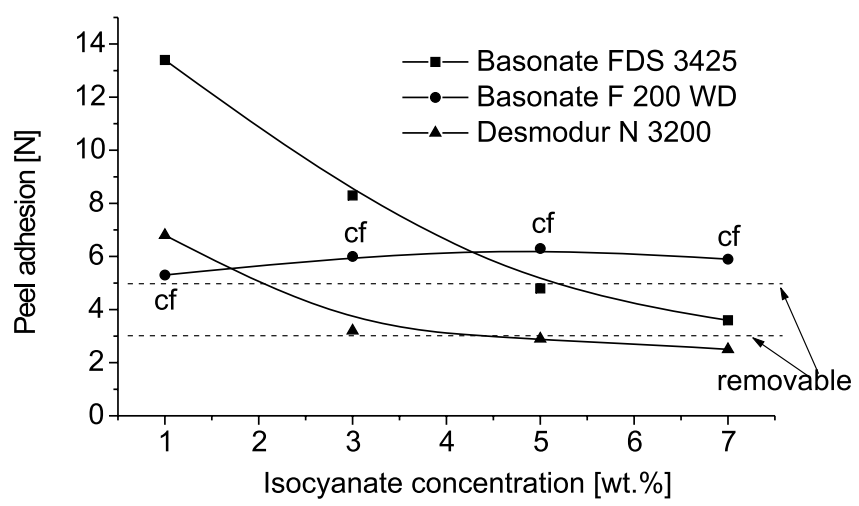

Figure 5. The effect of concentration and type of multifunctional isocyanates on peel adhesion

The increase of the multifunctional isocyanate concentration from 1 to $7 \mathrm{wt} . \%$ decreases the tack and peel adhesion performance. The concentration of isocyanate Desmodur N 3200 above 3 to 5 wt.\% is less favourable with respect to the removability of the pressure-sensitive adhesive. The best results of removability were achieved with the use of the multifunctional isocyanate Desmodur N 3200 in the amount between 3 to 5 according to PU polymer and about $5,0 \mathrm{wt} . \%$ of crosslinker Basonate FDS 3425 (Fig. 5).

Figure 6 shows the thermal resistance of the developed aqueous PU-PSA crosslinked using three investigated multifunctional isocyanate crosslinkers.

The multifunctional isocyanate Basonate F $200 \mathrm{WD}$ is inferior to the other tested isocyanate Basonate FDS 3425

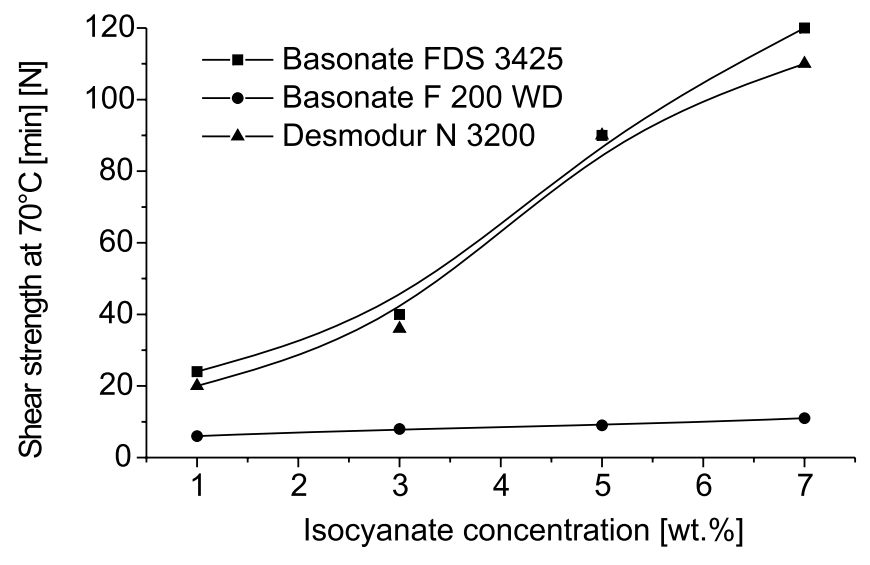

Figure 6. The effect of concentration and type of multifunctional isocyanates on shear strength

and Desomodur N 3200 although ensures cohesion at $70^{\circ} \mathrm{C}$ (Fig. 6).

The superiority of Basonate FDS 3425 and Desmodur N 3200 compared to Basonate F 200 WD used as crosslinking agents is obvious. They have much higher reactivity than Basonate F 200 WD. The application of Basonate F $200 \mathrm{WD}$ for the crosslinking of aqueous PUPSA stiffens the viscoelastic polyurethane polymer chains, which has negative influence on tack and peel adhesion and cohesion. By the use of Basonate F 200 WD for the crosslinking of aqueous PU-PSA by testing the tack and peel adhesion the cohesive failure (cf) was observed (Figs. 4 -5).

Generally, low tack, low peel adhesion and excellent shear strength have been achieved using the multifunctional isocyanates Basonate FDS 3425 and Desmodur N 3200 as crosslinkers for aqueous polyurethane pressure-sensitive adhesives. This justifies the use of the multifunctional isocyanates as the crosslinkers for PU-PSA dispersions in the case of protective films mainly.

In conclusion, the multifunctional isocyanate Desmodur N 3200 is a very good crosslinker for self-adhesive layers with low tack, low peel adhesion, removability and excellent cohesion for a wide range of application in the protective films area. The best performance for the application of the developed aqueous PU-PSA as protective films using Desmodure 3200 in the concentration between 3 and 4 wt.\%, were observed.

\section{CONCLUSIONS}

In this study, it was shown that it is possible to prepare novel aqueous polyurethane pressure-sensitive adhesives (PU-PSA) dispersions containing hydroxylated polybutadiene as the self-adhesives for protective films. The synthesised water-dispersible self-adhesive polyurethanes were stable for over 6 months. The versatility of the chemistry provides wide technical perspectives and allows very soft to hard chemical architectures. The increase of HTPB content and PPG amount with higher molecular weight increased the apparent viscosity of the end-products, the thermal resistance and the mechanical resistance of cast films. The developed water-dispersible polyurethane PSA are characterized by low tack, low adhesion and excellent cohesion after crosslinking with the selected multifunctional isocyanates. Protective films 
containing developed PU-PSA are characterized by excellent removability and stability of the removability level.

\section{LITERATURE CITED}

1. Benedek, I. (2006). Developments in pressure-sensitive products (2th ed.). Taylor \& Francis a CRC Press Book, USA.

2. Czech, Z. \& Koćmierowska, M. (2006).Water-dispersible polyurethane systems used as pressure-sensitive adhesives. Polimery 51, 456-459.

3. Hansen, G. \& Clemens, M. (2007). Polyurethane-based adhesives, systems for such adhesives, articles therefrom, and methods of making. DE Pat. 60028255.

4. Loclair, H. \& Czech, Z. (2005). Synthesis and application of removable and repositionable solvent-based acrylic selfadhesives. Polish J. Chem. Technol. 7(4), 17-20.

5. Kim, B.K., Ahn, B.U., Lee, M.H. \& Lee, S.K., (2006), "Design and properties of UV cured polyurethane dispersions", Progress in Organic Coating, vol.55, 194-200.

6. Czech, Z. \& Cieślik M., International Coating (2007), "Pressure-Sensitive Adhesives based on polyurethanes", 3, 45-48. 